\title{
Loss of Skill during Unemployment and TFP Differences across Countries
}

\author{
Victor Ortego-Marti* \\ University of California Riverside
}

\begin{abstract}
In an economy with search and matching frictions in which workers lose human capital during unemployment, TFP becomes endogenous and depends on workers' unemployment history. Using available estimates of labor market flows for a sample of OECD countries, this paper quantifies the amount of TFP differences due to skill losses during unemployment. Continental European countries, with their low job finding rates, exhibit the lowest TFPs. Nordic countries and Japan display the highest levels of TFP due to their high job finding rate relative to the separation rate. TFP in Anglo-Saxon countries stands in-between the two groups. The paper further studies the effect of hiring subsidies on the labor market and TFP.
\end{abstract}

JEL Classification: E24.

Keywords: Search and matching; endogenous TFP; loss of skills; unemployment history.

*Department of Economics, University of California Riverside. Sproul Hall 3132, Riverside CA 92521. Email: victor.ortego-marti@ucr.edu. Phone: 951-827-1502. 


\section{Introduction}

There is abundant evidence in the labor literature on the negative effects of unemployment on workers' wages. Workers separated from their jobs suffer large productivity losses compared to non-separated workers. At the aggregate level this implies that, other things equal, an economy in which workers experience long and frequent unemployment spells is less productive than an economy in which workers' unemployment spells are shorter and less frequent. Since the number and duration of unemployment spells are determined by how quickly workers find and lose jobs, an economy's productivity is partly determined by its labor market flows. Using empirical evidence on labor market flows for a sample of developed countries, this paper investigates to what extent observed TFP differences can be accounted for by search frictions in the labor market and the associated skill losses during unemployment. Alternatively, the paper asks the question: if labor market flows in a rigid market such as Spain, were instead similar to labor market flows in a more dynamic economy such as the US, how much would its productivity improve?

The paper develops a Diamond-Mortensen-Pissarides (DMP henceforth) search and matching framework in which workers lose some human capital during unemployment. ${ }^{1}$ In the model TFP is endogenous and depends on overall efficiency in the economy and the average human capital. If the economy has a dynamic labor market in which workers find jobs very quickly and lose their jobs infrequently, workers experience short unemployment durations and small human capital losses due to unemployment. As a result, human capital depends on workers' unemployment history - the cumulative duration of their unemployment spells. Since workers' unemployment history is determined by how quickly they find jobs and how frequently jobs are destroyed, the endogenous TFP is lower in economies with low job finding rates and high separation rates, other things equal.

The paper shows how the economy's average human capital and endogenous TFP depend on labor market flows and the amount of human capital depreciation during unemployment. In order to quantify TFP differences due to human capital depreciation, I focus on a sample of OECD countries for which empirical estimates of labor market flows exist. The paper draws from the empirical findings in Elsby, Hobijn, and Şahin (2013), who use a similar approach

\footnotetext{
${ }^{1}$ See Pissarides (2000) for a textbook treatment of the DMP framework.
} 
to Shimer (2005) and Shimer (2012) to estimate the job finding and separation rates in Australia, Canada, France, Germany, Ireland, Italy, Japan, New Zealand, Norway, Portugal, Spain, Sweden, United Kingdom and United States. Although this group consists of developed countries that may seem homogenous along a number of measures, as Elsby et al. (2013) show, the unemployment rate and labor market flows vary considerably among these countries. AngloSaxon and Nordic countries have high job finding and separation rates, whereas in continental Europe both rates are much lower. To calibrate the human capital depreciation rate during unemployment, the paper uses estimates from the Panel Study of Income Dynamics (PSID) in Ortego-Marti (2015b). The PSID estimation shows that an additional month of unemployment history is associated with a $1.22 \%$ wage loss, which is comparable to other estimates from the job displacement literature.

To measure the amount of TFP variations due to unemployment history the paper considers the following two exercises. First, assuming the same overall efficiency level across countries and that countries differ only in their labor market flows, I calculate the implied endogenous TFP. There is substantial variation across countries, and as in Elsby et al. (2013) there is a natural partition between continental European, Anglo-Saxon and Nordic countries. The highest TFP corresponds to Japan, with a value that is $6 \%$ larger than in the US. Although Japan does not have the highest job finding rate (which would reduce unemployment duration and lower human capital losses), its separation rate is extremely low, meaning that workers experience very few unemployment spells. At the other end of the spectrum Spain has the lowest TFP, which is not surprising given its high unemployment rates and sclerotic labor market. Spain's endogenous TFP is around $12 \%$ lower than in the US. To get a sense of the how big these TFP differences are, as in Caselli (2005) I compare the variance of the model's endogenous TFPs to the variance of observed TFPs, using TFP measures from the Penn World Table (PWT) 8.1. ${ }^{2}$ Between $25 \%$ and $31 \%$ of the variance in TFP can be explained by differences in human capital due to skill losses. ${ }^{3}$

Secondly, using observed TFP from the PWT 8.1, the paper asks the question: how much would each country's TFP change if labor market flows were the same as in the US? Not

\footnotetext{
${ }^{2}$ See Feenstra, Inklaar, and Timmer (2015) for details on the PWT 8.1.

${ }^{3}$ Other measures give larger values. The model explain around $45 \%$ of the observed mean absolute deviation and $88 \%$ of the observed $90-10$ percentile ratio.
} 
surprisingly, continental European countries have the largest predicted gains in productivity, ranging from a $4.8 \%$ increase in Portugal to $13.5 \%$ in Spain. Anglo-Saxon countries would see smaller gains, with an average gain of 3.8\%. On the other hand, Nordic countries and Japan would see productivity losses. Even though the job finding rate is higher in the US, their separation rate is relatively much smaller. The losses range from $4.5 \%$ in Sweden to $6 \%$ in Japan.

Finally, the paper analyzes the impact of a hiring subsidy on TFP. This policy has a positive impact on the labor market and stimulates job creation. Even though the country that would benefit the most from this policy is Spain, the analysis shows that it is not always true that countries with the lowest TFPs benefit the most from the policy. This happens because the impact of a hiring subsidy depends on several factors: the separation rate, the job finding rate, the ratio of the two - which determines the distribution of human capital - and the effect on labor market tightness - which determines the increase in the job finding rate. In particular, countries that have a bigger change in the job finding-separation rates ratio experience the highest TFP gains after the policy implementation.

Related literature. This paper is most closely related to Lagos (2006) and PetroskyNadeau (2013). Lagos (2006) introduces a model of TFP in a frictional labor market à la Mortensen and Pissarides (1994) and studies the effect of labor market policies on TFP. Petrosky-Nadeau (2013) studies TFP in a model with frictional labor and credit markets to explain the surge of TFP during the Great Recession despite a sharp decline in output and employment. As in these papers, I adopt a search and matching approach to the labor market which leads to an endogenous TFP. However, this paper focuses on the loss of skill during unemployment and provides a quantitative cross-country comparison. The paper is also broadly related to the vast literature on development accounting that aims to explain TFP variation across countries, especially to those studies that use the calibration approach. The literature is summarized in Caselli (2005), and includes among others Bils and Klenow (2000), Hall and Jones (1999), Klenow and Rodriguez-Clare (1997b), Klenow and Rodriguez-Clare (1997a), Lagakos (2015), Prescott (1998) and Restuccia, Yang, and Zhu (2008). However, none of these papers look at a frictional labor market or human capital losses due to unemployment.

There is substantial empirical evidence on the effects of unemployment on workers' wages. The job displacement literature finds large and very persistent earning losses among displaced 
workers. ${ }^{4}$ With the exception of Addison and Portugal (1989) and Neal (1995), most papers in this literature do not have information on unemployment duration and therefore can not provide an estimate of how wage losses depend on duration, which is key for the model. Therefore, this paper draws from the empirical evidence in Ortego-Marti (2015b) on the effects of unemployment history on workers' wages in the PSID.

This paper is also related to a literature that combines search frictions with human capital depreciation during unemployment. Two important references in this literature are Pissarides (1992) and Ljungqvist and Sargent (1998). In Pissarides (1992) unemployment becomes more persistent when unemployed workers lose skills during unemployment. Ljungqvist and Sargent (1998) offer an explanation for the high levels of unemployment in Europe compared to the US. ${ }^{5}$ However, papers in this literature do not quantify the fraction of TFP differences due to loss of skills during unemployment.

\section{A model of endogenous TFP}

This section extends the model in Ortego-Marti (2015a) to include a hiring subsidy. Consider the following labor market with search and matching frictions. Time is continuous. There are two agents in the economy, workers and firms. They are infinitely-lived and discount future income at a rate $r>0$. For simplicity, normalize the population size to one. It takes time for workers to find jobs and for firms to find applicants. To attract workers, firms post vacancies at a flow cost $c$. The number of matches formed is given by a matching function $m(u, v)$, where $u$ and $v$ denote the number of unemployed and employed workers. Assume that the matching function is concave, increasing in both its arguments and displays constant returns to scale. Given these assumptions, workers find jobs at a Poisson rate $f(\theta)=m(1, \theta)$ and firms fill their vacancies at a Poisson rate $q(\theta)=m\left(\theta^{-1}, 1\right)$, where $\theta$ denotes labor market tightness and is equal to the vacancy-unemployment ratio $v / u$. The properties of the matching function imply that $f(\theta)=\theta q(\theta)$. The job finding rate is increasing in $\theta$, i.e. $f^{\prime}(\theta)>0$, since higher

\footnotetext{
${ }^{4}$ Fallick (1996) and Kletzer (1998) review some of the findings in the early job displacement literature. See the references in Couch and Placzek (2010) for more recent results. An incomplete list of this big literature includes: Couch and Placzek (2010) and Jacobson, LaLonde, and Sullivan (1993), which use administrative data; Ruhm (1991) and Stevens (1997), which use the PSID; and Addison and Portugal (1989), Carrington (1993), Farber (1997), Neal (1995), Topel (1990) which use the Displaced Worker Survey (DWS) supplement of the Current Population Survey (CPS).

${ }^{5}$ See also Ljungqvist and Sargent (2007) and (2008).
} 
market tightness implies vacancies are more abundant relative to job seekers, so workers find jobs more quickly. Because of frictions in the labor market, some jobs are destroyed. Assume that separations occur exogenously at a Poisson rate $s$.

There is an overall labor efficiency to all matches in the economy, which I denote $p$. Labor productivity is further determined by workers' human capital. Workers lose human capital during unemployment at a constant rate $\delta$. Longer unemployment spells lead to larger human capital losses, so a worker's human capital depends on her complete history of unemployment spells. The empirical evidence shows that these losses are very persistent and depend on unemployment history, see section 3. Let $\gamma$ denote unemployment history, i.e. the cumulative duration of a worker's unemployment spells. For a given unemployment history $\gamma$, human capital is given by $h(\gamma)$. Normalizing $h(0)=1$, the assumption of a constant human capital depreciation rate during unemployment implies that $h(\gamma)=e^{-\delta \gamma}$.

This paper focuses on TFP differences due to differences in unemployment history. Therefore, human capital is net of other characteristics such as education. ${ }^{6}$ The productivity of a match is denoted $y$ and is given by the product of the economy's overall efficiency $p$ and the worker's human capital $h(\gamma)$, i.e.

$$
y=h(\gamma) p
$$

Employed workers earn wages $w(\gamma)$ and unemployed workers receive flow payments $b$, where $b$ is the value of non-market activities and includes unemployed benefits, home production and leisure.

Workers are identical when they join the labor market for the first time and their unemployment history $\gamma$ is 0 . However, due to search frictions they find and lose jobs at random and as a result they accumulate different unemployment histories. Let $G^{E}(\gamma)$ and $G^{U}(\gamma)$ denote the endogenous distribution of unemployment histories among employed and unemployed workers. To ensure stationarity of these distributions, assume that workers leave the labor force - or "die" - at a Poisson rate $\mu$. When workers leave the labor force they are replaced by new entrants with zero unemployment history.

\footnotetext{
${ }^{6}$ See Caselli (2005) and the references therein for studies that focus on TFP differences due to the quality of human capital and other determinants of human capital.
} 
Let $U(\gamma)$ and $W(\gamma)$ denote the value functions of an unemployed and employed worker with unemployment history $\gamma$. The Bellman equations for workers are given by

$$
\begin{aligned}
& (r+\mu) U(\gamma)=b+f(\theta)[\max \{W(\gamma), U(\gamma)\}-U(\gamma)]+\frac{\partial U(\gamma)}{\partial \gamma}, \\
& (r+\mu) W(\gamma)=w(\gamma)-s[W(\gamma)-U(\gamma)] .
\end{aligned}
$$

The Bellman equations satisfy that the return from the assets $U(\gamma)$ and $W(\gamma)$ must equal the payment flows plus any change in the capital value of the assets, where the effective discount rate $r+\mu$ takes into account that workers "die" at a rate $\mu$. The right-hand side of (2) captures that unemployed workers are paid income flow $b$. At a rate $f(\theta)$ they receive a job offer, which yields a net capital gain of $W(\gamma)-U(\gamma)$ if the offer is profitable (i.e. if $W(\gamma) \geq U(\gamma)$ ). Finally, the last term accounts for the depreciation of the asset value $U(\gamma)$ due to skill loss. Similarly, equation (3) captures that employed workers are paid wages $w(\gamma)$ and that at a rate $s$ they lose their jobs, which carries out a net loss of $W(\gamma)-U(\gamma)$.

Firms must pay flow costs $c$ while they post a vacancy. Following Lagos (2006) and Pissarides (2000), assume that firms receive a subsidy from the government at the time they are created. ${ }^{7}$ In particular, firms receive a payment of $\tau_{h} h(\gamma) p$, with $\tau_{h}$ constant. The size of the subsidy is thus proportional to the job's productivity. Let $J(\gamma)$ and $V$ denote the value functions of a filled job and an open vacancy. They satisfy the following Bellman equations

$$
\begin{aligned}
& (r+\mu) J(\gamma)=h(\gamma) p-w(\gamma)-s J(\gamma), \\
& r V=-c+q(\theta) \int_{0}^{\infty}\left[\max \left\{J(\Gamma)+\tau_{h} h(\Gamma) p, 0\right\}-V\right] d G^{U}(\Gamma) .
\end{aligned}
$$

The intuition is similar. From (4), a firm with a filled position receives a profit flow $h(\gamma) p-w(\gamma)$ and at a rate $s$ the job is destroyed, which implies a net capital loss of $J(\gamma)$. Similarly, the righthand side of (5) includes the flow costs $c$ of posting a vacancy and that at a rate $q(\theta)$ the firm draws a worker from the pool of unemployed workers, taking into account that the distribution of job seekers' unemployment history is $G^{U}(\gamma)$. If the match is profitable the firm hires the worker and receives the hiring subsidy, which carries a net capital gain of $J(\gamma)+\tau_{h} h(\Gamma) p-V$.

\footnotetext{
${ }^{7}$ As in Lagos (2006) and Pissarides (2000), for simplicity I ignore the government's financing constraint. One can achieve a balanced budget by introducing a tax on wages and benefits while still getting an effect of subsidies on market tightness.
} 
Due to search frictions, matches generate rents that must be split between the firm and the worker. Assume that wages are determined by Nash Bargaining, as in Nash (1950), where $\beta$ denotes workers' bargaining strength. Since the subsidy only applies at the time of hiring, similar to Lagos (2006) and Pissarides (2000) there are two wages: the wage $w_{0}(\gamma)$ that is negotiated at the time of hiring and the continuing wage $w(\gamma)$ that prevails after the worker is taken on. ${ }^{8}$ As in Pissarides (2000), the wage $w_{0}$ maximizes the Nash product

$$
w_{0}(\gamma)=\underset{w_{0}(\gamma)}{\arg \max }(W(\gamma)-U(\gamma))^{\beta}\left(J(\gamma)+\tau_{h} h(\gamma) p-V\right)^{1-\beta}
$$

In particular, the above bargaining problem takes into account that at the time of signing the contract, the firm's payoff is $J(\gamma)$ plus the amount of the subsidy $\tau_{h} p h(\gamma)$. The solution is given by

$$
(1-\beta)(W(\gamma)-U(\gamma))=\beta\left(J(\gamma)+\tau_{h} h(\gamma) p-V\right)
$$

Denote the surplus at the time of job creation by $S_{0}(\gamma)=W(\gamma)-U(\gamma)+J(\gamma)+\tau_{h} h(\gamma) p$. The solution implies that the worker is assigned a share $\beta$ of the surplus from the match and the firm the remaining share $1-\beta$, i.e. $W(\gamma)-U(\gamma)=\beta S_{0}(\gamma)$ and $J(\gamma)+\tau_{h} h(\gamma) p-V=(1-\beta) S_{0}(\gamma)$. Finally, assume that there is free entry in the market for vacancies, so firm entry drives the value of a vacancy to $V=0$.

Due to human capital decay, a match's surplus becomes zero if workers accumulate too much unemployment history. At that point, the worker collects all the output as a wage and is indifferent between market and non-market activities. The following proposition shows this result formally.

Proposition 1. There exists a unique $\bar{\gamma}$ such that

$$
\begin{aligned}
& (r+\mu) U(\bar{\gamma})=b, \quad \text { and } \\
& h(\bar{\gamma}) p=w(\bar{\gamma})
\end{aligned}
$$

The proof is included in the appendix, but the intuition is the following. Under the Nash

\footnotetext{
${ }^{8}$ In Pissarides (2000), $w_{0}$ and $w$ are called "outside" and "inside" wages.
} 
Bargaining assumption, the firm must compensate the worker for her outside option, in this case $U(\gamma)$. This outside option includes the constant value of non-market time $b$. Because the value of output declines with unemployment history, output will be unable to cover for payments $b$ to the worker if unemployment history is too large. When unemployment history reaches a certain level $\bar{\gamma}$, the value of the surplus is zero, and from (4) workers collect all the output in the form of wages, i.e. $w(\bar{\gamma})=h(\bar{\gamma}) p$. It follows from this result that $J(\bar{\gamma})=S(\bar{\gamma})=0$.

Proposition 1 implies that

$$
h(\bar{\gamma}) p=b .
$$

Once workers reach the terminal level $\bar{\gamma}$ output is used to compensate them for the value of non-market activities. In particular, $\bar{\gamma}$ is determined by

$$
\bar{\gamma}=-\frac{\log (b / p)}{\delta}
$$

I assume that when workers accumulate unemployment history beyond $\bar{\gamma}$, firms can assign them to a zero surplus position. This is similar to Pavoni and Violante (2007) and Pavoni, Setty, and Violante (2012), where workers can always be assigned to a low skill job that is not subject to human capital decay. This assumption is equivalent to assuming a lower bound for human capital and that workers who reach this lower bound are indifferent between market and non-market activities, which is reasonable and consistent with previous studies. Given this assumption, the Bellman equation for unemployment (2) becomes

$$
\begin{aligned}
& (r+\mu) U(\gamma)=b+f(\theta)(W(\gamma)-U(\gamma))+\frac{\partial U(\gamma)}{\partial \gamma}, \forall \gamma \leq \bar{\gamma} \\
& (r+\mu) U(\gamma)=b, \forall \gamma>\bar{\gamma}
\end{aligned}
$$

Similarly, the Bellman equation for vacancies (5) becomes

$$
r V=-c+q(\theta) \int_{0}^{\bar{\gamma}}\left(J(\Gamma)+\tau_{h} h(\Gamma) p\right) d G^{U}(\Gamma)+\int_{\bar{\gamma}}^{\infty} \tau_{h} h(\bar{\gamma}) p d G^{U}(\Gamma)
$$

where the last term of (11) captures that matches beyond $\bar{\gamma}$ yield a zero surplus, so firms only 
collect the hiring subsidy.

\subsection{Endogenous unemployment history distributions}

This section derives the stationary distributions $G^{E}(\gamma)$ and $G^{U}(\gamma)$ by looking at flows in the labor market. First, consider the group of unemployed workers with unemployment history lower than a given $\gamma$. In steady-state the flows in and out of this group must be equal to ensure stationarity, which implies the following flow equation

$$
g^{U}(\gamma) u+(f(\theta)+\mu) G^{U}(\gamma) u=s G^{E}(\gamma)(1-u)+\mu
$$

Consider now the overall group of unemployed workers. Flows out and into this group must be equal, which gives the following flow equation

$$
(f(\theta)+\mu) u=s(1-u)+\mu
$$

where the left-hand side captures the flows out and the right-hand side the flows into the unemployment pool. The above equation implies that the unemployment rate $u$ is given by

$$
u=\frac{s+\mu}{s+\mu+f(\theta)}
$$

Finally, consider the group of employed workers with unemployment history lower than a given $\gamma$. The following flow equation holds

$$
f(\theta) G^{U}(\gamma) u=(s+\mu) G^{E}(\gamma)(1-u)
$$

Substituting (14) into the above flow equation gives that $G^{U}(\gamma)=G^{E}(\gamma) \cdot{ }^{9}$ Combining this result with (12) and (14) implies the differential equation

$$
g^{U}(\gamma)+\frac{\mu(f(\theta)+s+\mu)}{s+\mu} G^{U}(\gamma)=\frac{\mu(f(\theta)+s+\mu)}{s+\mu} .
$$

\footnotetext{
${ }^{9}$ That the distributions $G^{U}(\gamma)$ and $G^{E}(\gamma)$ are equal makes the model tractable, but empirically the two distributions are likely to be different. One can break the feature that $G^{U}(\gamma)=G^{E}(\gamma)$ by assuming a match specific productivity, as in Ortego-Marti (2015b).
} 
The solution gives the endogenous distribution

$$
G^{U}(\gamma)=1-e^{-\alpha \gamma}
$$

where $\alpha \equiv \mu(f(\theta)+s+\mu) /(s+\mu)$, i.e. the distribution is exponential with parameter $\alpha$. Numerical simulations show that the above distribution matches very well the distribution of unemployment history for the PSID. ${ }^{10}$

The distribution of unemployment history depends on the size of labor market flows $f(\theta)$ and $s$, which vary across countries. When $f(\theta)$ is high, workers find jobs quickly and do not accumulate long unemployment histories. Similarly, a high $s$ implies that workers lose their jobs more frequently and thus accumulate longer unemployment history. Because average human capital depends on this distribution, the economy's productivity depends on labor market flows.

\subsection{Equilibrium}

Using the Bellman equations and the Nash Bargaining rule (7) gives wages as a function of $U(\gamma)$

$$
w_{0}(\gamma)=(1-\beta)(r+\mu) U(\gamma)+\beta\left[1+\tau_{h}(r+\mu+s)\right] h(\gamma) p
$$

Combining the Bellman equations gives the surplus

$$
S_{0}(\gamma)=\frac{h(\gamma) p\left[1+\tau_{h}(r+\mu+s)\right]-(r+\mu) U(\gamma)}{r+\mu+s}
$$

Substitute (7) and (19) into (2) and solve the differential equation to get $U(\gamma)$

$$
\begin{aligned}
(r+\mu) U(\gamma)= & {\left[e^{-\rho(\bar{\gamma}-\gamma)}\left(\frac{r+\mu+s-\beta f(\theta) T+\delta\left(\frac{r+\mu+s}{r+\mu}\right)}{r+\mu+s+\beta f(\theta)+\delta\left(\frac{r+\mu+s}{r+\mu}\right)}\right)+\frac{(r+\mu+s)\left(1-e^{-\rho(\bar{\gamma}-\gamma)}\right)}{r+\mu+s+\beta f(\theta)}\right] b } \\
& +\left[\frac{\beta f(\theta)(1+T)}{r+\mu+s+\beta f(\theta)+\delta\left(\frac{r+\mu+s}{r+\mu}\right)}\right] p,
\end{aligned}
$$

where $T$ and $\rho$ are defined as $T \equiv \tau_{h}(r+\mu+s)$ and $\rho=r+\mu+\beta f(\theta)(r+\mu) /(r+\mu+s)$ to simplify the notation.

\footnotetext{
${ }^{10}$ The results are available upon request.
} 
Combining the above equation with the Nash Bargaining rule (7) and free entry gives the job creation condition

$$
\frac{c}{q(\theta)}=\left(\frac{1-\beta}{r+\mu+s}\right) \Psi(f(\theta))+\tau_{h} b e^{-\alpha \bar{\gamma}}
$$

where $\Psi(f(\theta))=\int_{0}^{\infty}[h(\Gamma) p(1+T)-(r+\mu) U(\Gamma)] d G^{U}(\Gamma)$. Substituting $U(\gamma)$ from $(20)$ and integrating yields

$$
\begin{aligned}
\Psi(f(\theta))= & p\left[1+\tau_{h}(r+\mu+s)\right]\left(\frac{r+\mu+s+\delta\left(\frac{r+\mu+s}{r+\mu}\right)}{r+\mu+s+\beta f(\theta)+\delta\left(\frac{r+\mu+s}{r+\mu}\right)}\right)\left(\frac{\alpha}{\alpha+\delta}\right)\left(1-e^{-(\delta+\alpha) \bar{\gamma}}\right) \\
& -b\left(\frac{r+\mu+s-\beta f(\theta) T+\delta\left(\frac{r+\mu+s}{r+\mu}\right)}{r+\mu+s+\beta f(\theta)+\delta\left(\frac{r+\mu+s}{r+\mu}\right)}\right)\left(\frac{\alpha}{\rho-\alpha}\right)\left(e^{-\alpha \bar{\gamma}}-e^{-\rho \bar{\gamma}}\right) \\
& -b\left(\frac{r+\mu+s}{r+\mu+s+\beta f(\theta)}\right)\left[1-e^{-\alpha \bar{\gamma}}-\left(\frac{\alpha}{\rho-\alpha}\right)\left(e^{-\alpha \bar{\gamma}}-e^{-\rho \bar{\gamma}}\right)\right] .
\end{aligned}
$$

The job creation condition has some intuitive interpretation. Firms post vacancies until the expected cost - the left-hand side, which corresponds to the flow cost $c$ times the expected vacancy duration $1 / q(\theta)$ - equals expected future profits from hiring a worker. The job creation condition (21) gives the equilibrium labor market tightness $\theta$. Although it is somewhat cumbersome, it can be easily solved numerically. In particular, a convenient feature is that the right-hand side depends on $\theta$ only through the job finding rate $f(\theta)$.

\subsection{Total Factor Productivity}

The economy's TFP is endogenous and depends on the average human capital. When $\gamma \leq \bar{\gamma}$ a worker's productivity is given by $y=h(\gamma) p$, i.e. the product of her human capital $h(\gamma)$ and the overall efficiency in the economy $p$. Given the assumption of a lower bound for human capital, labor productivity satisfies $h(\gamma) p=h(\bar{\gamma}) p=b$ when $\gamma>\bar{\gamma}$. Let $\bar{y}$ denote the economy's TFP. Using the distribution $G^{U}(\gamma)$ derived in section 2.1 and integrating, $\bar{y}$ is given by

$$
\bar{y}=p\left(\frac{\alpha}{\alpha+\delta}\right)\left[1-e^{-(\alpha+\delta) \bar{\gamma}}\right]+b e^{-\alpha \bar{\gamma}}
$$

Clearly, TFP depends on labor market transition rates, as they determine the distribution of unemployment history among workers and the economy's average human capital. A higher 
job finding rate $f(\theta)$-whether this comes from an increase in $\theta$ or an increase in matching efficiency - leads to a higher average human capital and raises TFP. Similarly, an increase in $s$ implies that workers lose their jobs more frequently and accumulate more unemployment history, so the economy's average human capital depreciates.

Next, using evidence on labor market transition rates, I quantify what fraction of TFP differences can be explained by the effect of unemployment history on the economy's human capital.

\section{Empirical Evidence}

This section presents the empirical evidence used to calibrate the model and quantify TFP differences. One requires empirical estimates of labor market flows, the rate at which human capital depreciates during unemployment and observed TFP differences across the sample of countries.

Labor market flows. The paper draws from the findings in Elsby et al. (2013). The authors generalize the methodology in Shimer (2005) and Shimer (2012) to estimate the job finding and separation rates for a sample of fourteen OECD countries, namely Australia, Canada, France, Germany, Ireland, Italy, Japan, New Zealand, Norway, Portugal, Spain, Sweden, United Kingdom and the United States. ${ }^{11}$ Table 1 reproduces their estimates of the monthly flow rates and the unemployment rate for the sample of countries. ${ }^{12}$ The rates differ significantly, but one can see that Anglo-Saxon and Nordic countries tend to have very high job finding and separation rates compared to continental Europe.

Loss of skills during unemployment. To calibrate the human capital depreciation rate during unemployment, the paper uses estimates in Ortego-Marti (2015b) based on the 19681997 waves of the PSID, a large panel of US workers. Using a panel structure for the estimation is important for a number of reasons. First, there may be some unobserved characteristics that make some workers more productive than others. If less productive workers are more

\footnotetext{
${ }^{11}$ The sample is selected based on available data and comparability across countries. See Table 1 in Elsby et al. (2013) for more details on the data sources for each country. See also Hobijn and Şahin (2009) and Petrongolo and Pissarides (2008) for alternative estimates for a group of OECD countries using different estimation techniques.

${ }^{12}$ See table 2 in Elsby et al. (2013).
} 
likely to be unemployed, the estimation may be biased. Second, when a worker joins the sample previous unemployment history is unknown. However, when a worker joins the sample, prior unemployment history remains constant in later observations. By controlling for workers' constant unobserved characteristics, fixed effects estimation solves these two problems. Finally, a panel structure allows us to estimate how wage losses depend on unemployment duration, which is needed in the calibration.

Although the calibration uses the estimates based on the PSID, the estimated losses are likely similar for the other OECD countries in the sample, given that this is a fairly homogenous group of countries. For example, Burda and Mertens (2001), Eliason and Storrie (2006) and Schmieder, von Wachter, and Bender (2010) find similar effects in Germany and Sweden. This assumption follows the approach in many papers in the development accounting literature, which exploit differences in the quantity of human capital (as measured for example by years of schooling), assuming the same quality of human capital across countries. Although some papers find that differences in human capital quality play an important role, they mostly explain productivity differences between developed and developing countries, or among developing countries.

The PSID asks workers how many weeks they were unemployed in the previous year. Using the answers to this question, Ortego-Marti (2015b) constructs the variable Unhis, which contains each worker's unemployment history in months, and regresses the log of wages on Unhis and other covariates $X$ standard in Mincerian regressions. The regression model is given by

$$
\log w_{i t}=\alpha_{i}-\delta U_{n h i s_{i t}}+\beta X_{i t}+\varepsilon_{i t} .
$$

Fixed effects regression controls for all constant characteristics, so in column (1) X includes potential experience (cubic), regional dummies, and one-digit occupational dummies. The regression gives an estimate for $\delta$ of 0.0122 , which is the value used in the rest of the paper. Further, as Ortego-Marti (2015b) shows, these wage losses are very persistent. ${ }^{13}$

In the job displacement literature, Addison and Portugal (1989) and Neal (1995) provide

\footnotetext{
${ }^{13} \mathrm{~A}$ month of unemployment history that was experienced more than 5 years ago is associated with a $1.04 \%$ wage loss. As Ortego-Marti (2015b) shows, the result are very robust to different specifications of the estimation model.
} 
comparable estimates and find similar results. ${ }^{14}$ Neal (1995) Table 3, reports that an additional week of unemployment is associated with a $0.37 \%$ wage loss. This implies a monthly depreciation rate of $1.59 \%$. Addison and Portugal (1989) find a similar monthly value of $1.44 \%$. These estimates are larger compared to $1.22 \%$ from the above regression, but they are otherwise similar. These papers generally find larger values because they focus on displaced workers, a subset of the unemployed that are likely to suffer larger losses. Pavoni and Violante (2007) use a monthly depreciation rate of $1.5 \%$ partly based on the evidence in Addison and Portugal (1989) and Neal (1995). Using these values would yield larger differences in TFP due to loss of skills, so the results of this paper can be thought of as a lower bound on TFP differences.

TFP differences. Evidence on observed TFP differences comes from the Penn World Table 8.1 (PWT 8.1). Feenstra et al. (2015) provide detailed information on the construction of the PWT 8.1, and in particular on how TFP is estimated. Their findings are reported in table 2. The PWT 8.1 provides countries' TFP relative to the US, so TFP equals 1 in the US.

\section{TFP differences due to loss of skills}

One can use the model without subsidies $\left(\tau_{h}=0\right)$ to quantify the amount of productivity differences due to skill decay during unemployment. Without hiring subsidies, the quantitative analysis only requires the calibration of parameters $\{\delta, f, s, \mu, b\}$. The calibration of $f, s$ and $\delta$ uses the empirical evidence in the previous section. The rate at which workers leave the labor force $\mu$ is chosen to match an average working live of 40 years, which implies a monthly value of 0.0021. Finally, the value for $b$ is taken from Hall and Milgrom (2008) based on data on UI replacement ratios and the empirical Frisch elasticity of labor supply. In particular, the target for $b$ is a replacement ratio $b / \bar{y}$ of 0.73 . Given that countries have different TFPs, I choose $b$ for the country with the highest TFP (Japan), since lower values of $b$ would amplify TFP differences. This calibration thus provides a lower bound on the effects of unemployment history. ${ }^{15}$

The economy's TFP is determined by $\bar{y}$ in (23) and depends on: (1) overall efficiency $p$,

\footnotetext{
${ }^{14}$ Most estimates from the displacement literature, in particular those that use administrative data, are not directly comparable because they lack information on unemployment duration.

${ }^{15}$ Results are similar if one chooses average TFP instead.
} 
which plays the role of the parameter $A$ in a Cobb-Douglas production function $y=A k^{\alpha} l^{1-\alpha}$; and (2), on average human capital in the economy, which is determined by labor market flows and workers' average unemployment history. Similar to Caselli (2005), suppose that overall efficiency $p$ is the same across countries. I then compute the model's endogenous TFP using countries' labor market flows and compare the resulting differences to the observed variation in TFP. In other words, this exercise answers the question: how does the predicted distribution of productivities in the model with unemployment history compare to the distribution we observe in the data? Or alternatively, how much of the observed TFP differences can be explained by the model with unemployment history and loss of skills?

The results are reported in table 2. Similar to Elsby et al. (2013), one can see a natural partition between Anglo-Saxon, Nordic and continental European countries. Continental European countries, not surprisingly, exhibit the lowest levels of TFP. Separation rates are much lower compared to the US in France, Germany, Italy and Portugal, with an average 0.005 at monthly frequencies. The separation rate is thus around 7 times higher in the US. However, the job finding rate is so much higher in the US (it is more than 9 times the average for these countries) that US workers accumulate less unemployment history and suffer fewer human capital losses. Overall TFP for these countries is on average 7\% lower than in the US. The same intuition applies to Anglo-Saxon countries, although their predicted TFP is only 3.9\% lower than in the US. As one would expect given its sclerotic labor market, Spain is the country with the lowest endogenous TFP. Although its job finding rate is similar to other continental European countries, its separation rate is twice as large. As a result, Spain's predicted TFP is around $12 \%$ lower than in the US. By contrast, the endogenous TFP in Nordic countries and Japan is on average $5.4 \%$ higher than in the US, as workers experience unemployment less often. In Nordic countries and Japan the job finding rate is around half of the value in the US, but the job separation rate is more than 3 times as large in the US. The country with the highest TFP is Japan, due to its very low job separation rate combined with a relatively high job finding rate.

When comparing the observed TFPs and the model's endogenous TFPs in table 2, a few observations are worth noting. Consider Japan's TFP. Empirically, Japan has a much lower TFP than the US, almost $20 \%$ lower. Why productivity is so much lower in Japan is still an open question in the literature and most papers treat TFP differences as exogenous, see 
for example Hayashi and Prescott (2002) and Prescott (2002). Some of the explanations put forth by the literature include demographic dynamics (Japan has very high and increasing dependency ratios), the financial system and monetary policy. ${ }^{16}$ This section assumes that overall efficiency $p$ is the same across countries, whereas the observed TFP is likely affected by other factors. This approach allows us to quantify the productivity differences arising from the fact that Japan's workers spend less time in unemployment and suffer fewer human capital losses than US workers. That Japan's endogenous TFP is 1.064 implies that avoiding the skill losses from unemployment give Japan a productivity advantage of $6.4 \%$ over the US. Consider the other end of the spectrum. Given Spain's labor market flows, its endogenous TFP is 0.881 . This captures that because Spain's workers sit in unemployment for so long, Spain suffers a productivity loss of around $12 \%$ due to human capital depreciation compared to the US. ${ }^{17}$

\subsection{Measures of productivity dispersion}

Similar to Caselli (2005), one can measure the fraction of the variance of observed TFPs that can be explained by the variance of the endogenous TFP $\bar{y}$. In other words, I calculate the following measure $\Delta_{v a r}$

$$
\Delta_{v a r}=\frac{\operatorname{var}[\log (\bar{y})]}{\operatorname{var}\left[\log \left(y^{e m p}\right)\right]},
$$

where $y^{e m p}$ denotes the observed TFP reported in table 2. The above measure gives a value for $\Delta_{v a r}$ of 0.246 , meaning that the model explains around $25 \%$ of the observed TFP. To get a sense of how big this fraction is, Caselli (2005) reports that a factor-only model with capital can explain around 39\% of the observed variation in productivity, including developing countries. This suggests that the skill losses occurring during unemployment play an important role in explaining cross-country productivities. The ratio of the variance of TFPs $\tilde{\Delta}_{v a r}=$ $\operatorname{var}(\bar{y}) / \operatorname{var}\left(y^{e m p}\right)$ is similar and equal to $31 \%$.

One can alternatively measure TFP differences using the mean absolute deviation instead

\footnotetext{
${ }^{16}$ For example, see Bart van Ark (2008), Kobayashi (2007) and Rodriguez-Lopez and Torres (2012).

${ }^{17}$ Section 4.2 calibrates $p$ so that the endogenous TFP matches its empirical counterpart.
} 
of the variance. Let $\Delta_{d e v}$ denote the following measure

$$
\Delta_{\text {dev }}=\frac{\sum\left|\log (\bar{y})-\mu_{\bar{y}}\right|}{\sum\left|\log \left(y^{e m p}\right)-\mu_{y^{e m p}}\right|},
$$

where $\mu_{\bar{y}}$ denotes the mean of $\log (\bar{y})$ and $\mu_{y^{e m p}}$ is defined similarly. This measure delivers larger TFP differences, with $\Delta_{\text {dev }}$ equal to $48 \%$. However, this may be due to the fact that the mean absolute deviation is more sensitive to outliers. ${ }^{18}$

Finally, Caselli (2005) suggests an alternative measure that uses the 90-10 percentile ratio. Define $\Delta_{90 / 10}$ as

$$
\Delta_{90 / 10}=\frac{\bar{y}^{90} / \bar{y}^{10}}{y_{e m p}^{90} / y_{e m p}^{10}}
$$

where $\bar{y}^{i}$ and $y_{\text {emp }}^{i}$ are the $i$-percentiles of $\bar{y}$ and $y^{e m p}$. The value for $\Delta_{90 / 10}$ is 0.88 , i.e. loss of skills explain up to $88 \%$ of the 90-10 percentile ratio of observed TFPs. Overall, all measures show that productivity differences due to loss of skills are sizable.

\subsection{TFP with different overall efficiency}

The previous sections assumed the same overall efficiency $p$ across countries. However, overall efficiency $p$ differs across countries due to other factors. To gain a further understanding of the magnitude of productivity differences due to skill loss, consider the following alternative exercise. Suppose now that overall efficiency $p$ is different across countries and calibrate $p$ so that the endogenous TFP $\bar{y}$ matches its empirical value. I then ask the question: how would TFP change for each country if labor market flows were the same as in the US? This exercise tells us how much productivity would increase in, say, Spain if we could somehow reform the labor market so that flows are the same as in the US, taking into account initial differences in overall efficiency.

The results are reported in table 2 , last column. This exercise gives a similar picture. Continental European countries would see the biggest productivity improvements. On average, productivity gains for this group would be around 8.5\% (7.2\% excluding Spain). Spain would see the highest improvement with an increase of 13.5\%. In Anglo-Saxon countries productiv-

\footnotetext{
${ }^{18}$ The mean absolute value is an $L^{1}$ measure, whereas the variance is $L^{2}$.
} 
ity would increase by an average 4.1\%. By contrast, Nordic countries and Japan would see an average loss of $5.1 \%$. With US labor market flows their workers would accumulate more unemployment history and experience more human capital losses.

\section{Effect of hiring subsidies}

Hiring subsidies are a policy that stimulates job creation and thus improves human capital. This section quantifies the effect of this policy on TFP. In particular, this section answers the question: do countries that suffer the largest human capital losses from unemployment benefit the most from the policy?

Without subsidies, TFP can be quantified with knowledge of $\{\delta, f, s, \mu, b\}$ alone. In particular, equilibrium market tightness $\theta$ is not required because TFP depends on $\theta$ only through the job finding rate $f(\theta)$. Since there are empirical estimates for the job finding rate, it can be treated as a parameter. However, this is no longer true with hiring subsidies and some additional parameters must be calibrated. Assume that the job finding rate takes the form $m_{0} \theta^{1-\eta}$, which implies that $q(\theta)=m_{0} \theta^{-\eta}$, where $m_{0}$ is matching efficiency and $1-\eta$ is the elasticity of the job finding rate with respect to market tightness. The calibration requires additional parameter values for $\left\{m_{0}, c, \eta, \beta\right\}$. Following Pissarides (2009), set $\eta$ equal to 0.5, which is within the range of plausible estimates given by Petrongolo and Pissarides (2001). ${ }^{19}$ As is standard in the literature, assume $\beta=\eta$ to satisfy the Hosios-Mortensen-Pissarides condition.

The two targets used to calibrate $m_{0}$ and $c$ are: (1) the job finding rate $m_{0} \theta^{1-\eta}$ must match the observed job finding rate; (2) the job creation condition (21) must hold. However, as in Shimer (2005), one can normalize either $m_{0}$ or $c$. This can easily be seen by looking at (21). Let $\tilde{\Psi}(f(\theta))$ denote the right-hand side of (21), which depends on $\theta$ only through $f(\theta)$. Rearranging, this implies that $\theta=\left\{c /\left[\tilde{\Psi}(f(\theta)) m_{0}\right]\right\}^{-1 / \eta}$. Given that $f(\theta)$ must match its empirical value, $\theta$ depends on the ratio $c / m_{0}$, not the individual values for $c$ and $m_{0}$. Based on this observation, let $c=0.5$, which is similar to the value used in Hagedorn and Manovskii (2008) and Silva and Toledo (2009). Using this value and the empirical job finding rate gives equilibrium $\theta .{ }^{20}$

\footnotetext{
${ }^{19}$ One could use a different value for each country. However, as Petrongolo and Pissarides (2001) show, the elasticity is similar among OECD countries.

${ }^{20}$ One can alternatively choose a value for $\theta$ (as in Pissarides (2009)) or normalize $\theta=1$ (as in Shimer (2005)), or calibrate the value for $m_{0}$ and find the other reamaining parameters similarly by matching the empirical job finding rate and ensuring that the job creation condition holds. All these alternatives give the exact same results for the reasons exposed in the text.
} 
Once the required parameters are calibrated, I solve for the equilibrium market tightness with a positive hiring subsidy. In particular, assume $\tau_{h}$ equals 0.5 , meaning that the government gives a one-off payment at the time of job creation that equals half the match's output. Equilibrium tightness is determined by the job creation condition $(21)$ (now with $\tau_{h}=0.5$ ), which can be easily solved numerically by iteration. Equilibrium market tightness then determines the new job finding rate after the policy is implemented, and thus the average human capital and the economy's TFP.

Table 3 reports the ratio of TFP with a hiring subsidy to TFP in the model with no subsidy. As expected, hiring subsidies have a positive effect on the labor market and encourage job creation. This leads to lower average unemployment history and an overall improvement in average human capital and TFP. However, a similar partition of countries between AngloSaxon, Nordic and continental European is less clear now. Continental European countries, excluding Spain, together with Australia, Ireland, New Zealand and the UK would see middle range productivity gains, with an average gain of $1.06 \%$. Nordic countries and Japan would see the lowest gains with an average of $0.44 \%$. Canada, Spain and the US would see the largest gains with an average of $1.83 \%$.

This pattern of productivity gains is slightly different from the conclusions in section 4 because the effect of a hiring subsidy on TFP depends on a number of factors: the job finding and the separation rates separately, the ratio of the two rates and the size of the market tightness response. One can see this by looking at the change in TFP for a given change in the subsidy rate $\tau_{h}$

$$
\frac{d \bar{y}}{d \tau_{h}}=\frac{\partial \bar{y}}{\partial f(\theta)}(1-\eta) f(\theta) \frac{d \theta / d \tau_{h}}{\theta}
$$

where

$$
\frac{\partial \bar{y}}{\partial f(\theta)}=p\left[\frac{\delta}{(\alpha+\delta)^{2}} \frac{\mu}{s+\mu}\left(1-e^{-(\alpha+\delta) \bar{\gamma}}\right)+\bar{\gamma} \frac{\alpha}{\alpha+\delta} \frac{\mu}{s+\mu} e^{-(\alpha+\delta) \bar{\gamma}}\right]-b \bar{\gamma} \frac{\mu}{s+\mu} e^{-\alpha \bar{\gamma}}
$$

The ratio of the job finding to the separation rate determines the shape of the distribution of human capital, so in general the change in this ratio predicts very well the policy's impact on TFP. Quantitatively, Spain, Canada and the US see the largest increase in the ratio following 
the policy, with an average increase of $17.75 \%$ (Spain has the highest increase, with a $24.48 \%$ increase). By contrast, countries with mid-range gains experience an average increase of $9.19 \%$ in this ratio, and Nordic countries plus Japan see an increase of only $3.23 \%$. These results suggest that one should be cautious about the relative effectiveness of hiring subsidies, since countries with the highest levels of unemployment history are not necessarily the ones to benefit the most from these policies.

\section{Conclusion}

If workers lose some human capital during unemployment, how fast workers find jobs and how long they hold on to them affects the economy's productivity and TFP. The paper develops a search and matching model of the labor market in which workers lose skills during periods of unemployment. The model shows that TFP is endogenous and depends on labor market flows and workers' unemployment history, since these affect the economy's average human capital. Using available estimates in the literature for labor market flows in a sample of OECD countries, the paper quantifies the amount of TFP differences due to loss of skills during unemployment. The paper shows that one can partition the sample among Anglo-Saxon countries, Nordic countries plus Japan, and continental European countries. Continental European countries exhibit the lowest TFPs due to their more sclerotic labor markets. With high job finding rates but with also relatively high separation rates, Anglo-Saxon countries exhibit mid-range values of endogenous TFP. By contrast, Nordic countries and Japan exhibit the largest TFPs. The paper also analyzes the effect of hiring subsidies. Hiring subsidies stimulate job creation and increase TFP, as they raise the job finding rate and lower average unemployment histories. However, the model shows that it is not always the countries with the lowest levels of TFP that benefits the most from the policy.

A few extensions are worth pursuing. In the model there is no participation margin. However, it is reasonable to think that in reality some workers do not participate in the labor market due to very low skills. This selection effect is likely to amplify the effect of labor market policies such as hiring subsidies. For simplicity, separations are exogenous in the model. It would be interesting to see how endogenous separation would affect the labor market and the endogenous TFP. Endogenous separations seem likely to amplify the role of skill losses. These extensions, though important, are left for future work. 


\section{Appendix}

\section{Proof of Proposition 1}

Let $S(\gamma)$ denote the match surplus after hiring, i.e. $S(\gamma) \equiv J(\gamma)+W(\gamma)-U(\gamma)$ (since there are no firing costs). Nash Bargaining implies that

$$
\begin{aligned}
& W(\gamma)-U(\gamma)=\beta S(\gamma) \\
& J(\gamma)=(1-\beta) S(\gamma)
\end{aligned}
$$

Using (3) and (4) in the main text gives

$$
\begin{aligned}
& (r+\mu+s)(W(\gamma)-U(\gamma))=w(\gamma)-(r+\mu) U(\gamma) \\
& (r+\mu+s) J(\gamma)=h(\gamma) p-w(\gamma)
\end{aligned}
$$

Combining the above equations with the Nash Bargaining condition and solving for wages gives

$$
S(\gamma)=\frac{h(\gamma) p-(r+\mu) U}{r+\mu+s}
$$

Given that an unemployed worker can always choose to keep the value of non-market time $b$, clearly $(r+\mu) U(\gamma) \geq b$. Therefore

$$
S(\gamma) \leq \frac{h(\gamma) p-b}{r+\mu+s}
$$

As $\gamma$ tends to infinity, productivity $h(\gamma) p$ tends to zero, so there exists a $\bar{\gamma}$ such that $S(\bar{\gamma})=0$. As a result, $J(\bar{\gamma})=0$ and $W(\bar{\gamma})=U(\bar{\gamma})$. In particular, using (2) and (4) it follows that

$$
\begin{aligned}
& h(\bar{\gamma}) p=w(\bar{\gamma}) \\
& (r+\mu) U(\bar{\gamma})=b
\end{aligned}
$$




\section{References}

Addison, J. T., Portugal, P., 1989. Job displacement, relative wage changes, and duration of unemployment. Journal of Labor Economics 7 (3), pp. 281-302.

Bart van Ark, Mary O’Mahony, M. P. T., 2008. The productivity gap between Europe and the United States: Trends and causes. The Journal of Economic Perspectives 22 (1), 25-44.

Bils, M., Klenow, P. J., 2000. Does schooling cause growth? America Economic Review 90 (5), pp. 1160-1183.

Burda, M. C., Mertens, A., 2001. Estimating wage losses of displaced workers in Germany. Labour Economics 8 (1), $15-41$.

Carrington, W. J., 1993. Wage losses for displaced workers: Is it really the firm that matters? Journal of Human Resources 28 (3), pp. 435-462.

Caselli, F., 2005. Chapter 9: Accounting for cross-country income differences. Vol. 1, Part A of Handbook of Economic Growth. Elsevier, pp. 679 - 741.

Couch, K. A., Placzek, D. W., 2010. Earnings losses of displaced workers revisited. American Economic Review 100 (1), 572-89.

Eliason, M., Storrie, D., 2006. Lasting or latent scars? Swedish evidence on the long-term effects of job displacement. Journal of Labor Economics 24 (4), pp. 831-856.

Elsby, M., Hobijn, B., Şahin, A., 2013. Unemployment dynamics in the OECD. Review of Economics and Statistics 95 (2), 530-548.

Fallick, B. C., 1996. A review of the recent empirical literature on displaced workers. Industrial and Labor Relations Review 50 (1), pp. 5-16.

Farber, H. S., 1997. The changing face of job loss in the United States, 1981-1995. Brookings Papers on Economic Activity: Microeconomics, 55-128.

Feenstra, R. C., Inklaar, R., Timmer, M. P., 2015. The next generation of the Penn World Table. American Economic Review 105 (10), 3150-82.

Hagedorn, M., Manovskii, I., 2008. The cyclical behavior of equilibrium unemployment and vacancies revisited. American Economic Review 98 (4), pp. 1692-1706.

Hall, R. E., Jones, C. I., 1999. Why do some countries produce so much more output per worker than others? Quarterly Journal of Economics 114 (1), 83-116.

Hall, R. E., Milgrom, P. R., 2008. The limited influence of unemployment on the wage bargain. American Economic Review 98 (4), pp. 1653-1674.

Hayashi, F., Prescott, E. C., 2002. The 1990s in Japan: A lost decade. Review of Economic Dynamics 5 (1), $206-235$.

Hobijn, B., Şahin, A., 2009. Job-finding and separation rates in the OECD. Economics Letters $104(3), 107-111$. 
Jacobson, L. S., LaLonde, R. J., Sullivan, D. G., 1993. Earnings losses of displaced workers. American Economic Review 83 (4), pp. 685-709.

Klenow, P. J., Rodriguez-Clare, A., 1997a. Economic growth: A review essay. Journal of Monetary Economics 40 (3), $597-617$.

Klenow, P. J., Rodriguez-Clare, A., 1997b. The neoclassical revival in Growth Economics: Has it gone too far? In: NBER Macroeconomics Annual 1997, Volume 12. MIT Press, pp. 73-114.

Kletzer, L. G., 1998. Job displacement. Journal of Economic Perspectives 12 (1), pp. 115-136.

Kobayashi, K., 2007. Payment uncertainty and the productivity slowdown. Macroeconomic Dynamics 11, 231-248.

Lagakos, D., 2015. Explaining cross-country productivity differences in retail trade. Forthcoming, Journal of Political Economy.

Lagos, R., 2006. A model of TFP. Review of Economic Studies 73 (4), 983-1007.

Ljungqvist, L., Sargent, T. J., 1998. The European unemployment dilemma. Journal of Political Economy 106 (3), 514-550.

Ljungqvist, L., Sargent, T. J., 2007. Understanding European unemployment with matching and search-island models. Journal of Monetary Economics 54 (8), 2139 - 2179.

Ljungqvist, L., Sargent, T. J., 2008. Two questions about European unemployment. Econometrica $76(1), 1-29$.

Mortensen, D. T., Pissarides, C. A., 1994. Job creation and job destruction in the theory of unemployment. Review of Economic Studies 61 (0), 397-415.

Nash, John F., J., 1950. The bargaining problem. Econometrica 18 (2), pp. 155-162.

Neal, D., 1995. Industry-specific human capital: Evidence from displaced workers. Journal of Labor Economics 13 (4), pp. 653-677.

Ortego-Marti, V., 2015a. The cyclical behavior of unemployment and vacancies with loss of skills during unemployment. Forthcoming, Macroeconomic Dynamics.

Ortego-Marti, V., 2015b. Unemployment history and frictional wage dispersion. Forthcoming, Journal Monetary Economics.

Pavoni, N., Setty, O., Violante, G. L., 2012. Search and work in optimal welfare programs. Mimeo.

Pavoni, N., Violante, G. L., 2007. Optimal welfare-to-work programs. Review of Economic Studies 74 (1), 283-318.

Petrongolo, B., Pissarides, C. A., 2001. Looking into the black box: A survey of the matching function. Journal of Economic Literature 39 (2), pp. 390-431. 
Petrongolo, B., Pissarides, C. A., 2008. The ins and outs of European unemployment. American Economic Review 98 (2), pp. 256-262.

Petrosky-Nadeau, N., 2013. TFP during a credit crunch. Journal of Economic Theory 148 (3), $1150-1178$.

Pissarides, C. A., 1992. Loss of skill during unemployment and the persistence of employment shocks. Quarterly Journal of Economics 107 (4), pp. 1371-1391.

Pissarides, C. A., 2000. Equilibrium Unemployment Theory. MIT Press, Cambridge.

Pissarides, C. A., 2009. The unemployment volatility puzzle: Is wage stickiness the answer? Econometrica 77 (5), 1339-1369.

Prescott, E. C., 1998. Needed: A theory of Total Factor Productivity. International Economic Review 39 (3), 525-551.

Prescott, E. C., 2002. Prosperity and depression. American Economic Review 92 (2), 1-15.

Restuccia, D., Yang, D. T., Zhu, X., 2008. Agriculture and aggregate productivity: A quantitative cross-country analysis. Journal of Monetary Economics 55 (2), $234-250$.

Rodriguez-Lopez, J., Torres, J. L., 2012. Technological sources of productivity growth in Germany, Japan, and the United States. Macroeconomic Dynamics 16, 133-150.

Ruhm, C. J., 1991. Are workers permanently scarred by job displacements? American Economic Review 81 (1), pp. 319-324.

Schmieder, J. F., von Wachter, T., Bender, S., 2010. The long-term impact of job displacement in Germany during the 1982 recession on earnings, income, and employment. Mimeo.

Shimer, R., 2005. The cyclical behavior of equilibrium unemployment and vacancies. American Economic Review 95 (1), 24-49.

Shimer, R., 2012. Reassessing the ins and outs of unemployment. Review of Economic Dynamics $15(2), 127-148$.

Silva, J. I., Toledo, M., 5 2009. Labor turnover costs and the cyclical behavior of vacancies and unemployment. Macroeconomic Dynamics 13, 76-96.

Stevens, A. H., 1997. Persistent effects of job displacement: The importance of multiple job losses. Journal of Labor Economics 15 (1), pp. 165-188.

Topel, R., 1990. Specific capital and unemployment: Measuring the costs and consequences of job loss. Carnegie-Rochester Conference Series on Public Policy 33 (0), 181 - 214. 
Table 1: Labor Market Flows

\begin{tabular}{lccc}
\hline \hline Country & Unemployment rate & Job finding rate & Separation rate \\
\hline Australia & $7.1 \%$ & $22.8 \%$ & $1.7 \%$ \\
Canada & $8.5 \%$ & $26.1 \%$ & $2.4 \%$ \\
France & $8.1 \%$ & $7.7 \%$ & $0.7 \%$ \\
Germany & $8.3 \%$ & $6.0 \%$ & $0.5 \%$ \\
Ireland & $10.8 \%$ & $5.9 \%$ & $0.6 \%$ \\
Italy & $9.8 \%$ & $4.3 \%$ & $0.4 \%$ \\
Japan & $3.3 \%$ & $18.9 \%$ & $0.6 \%$ \\
New Zealand & $6.4 \%$ & $28.5 \%$ & $1.7 \%$ \\
Norway & $4.1 \%$ & $38.5 \%$ & $1.6 \%$ \\
Portugal & $6.2 \%$ & $6.3 \%$ & $0.4 \%$ \\
Spain & $15.4 \%$ & $6.3 \%$ & $1.1 \%$ \\
Sweden & $4.3 \%$ & $29.2 \%$ & $1.2 \%$ \\
UK & $7.7 \%$ & $13.9 \%$ & $1.0 \%$ \\
US & $6.1 \%$ & $56.5 \%$ & $3.6 \%$ \\
\hline
\end{tabular}

Note.- Rates are expressed monthly. The estimates are drawn from Table 2 in Elsby et al. (2013). See section 3 for details. 
Table 2: TFP DifFERENCES

\begin{tabular}{llll}
\hline \hline Country & $\begin{array}{l}\text { Observed } \\
\text { TFP (US=1) }\end{array}$ & $\begin{array}{l}\text { Endogenous } \\
\text { TFP (US=1) }\end{array}$ & $\begin{array}{l}\text { Productivity } \\
\text { change, US flows }\end{array}$ \\
\hline Continent. European & & & \\
France & 1.025 & 0.932 & $7.32 \%$ \\
Germany & 0.898 & 0.932 & $7.33 \%$ \\
Italy & 0.976 & 0.913 & $9.48 \%$ \\
Portugal & 0.733 & 0.954 & $4.79 \%$ \\
Spain & 0.931 & 0.881 & $13.50 \%$ \\
Anglo-Saxon & & & \\
Australia & 0.873 & 0.972 & $2.91 \%$ \\
Canada & 0.963 & 0.950 & $5.24 \%$ \\
Ireland & 1.076 & 0.916 & $9.11 \%$ \\
New Zealand & 0.790 & 1.001 & $-0.09 \%$ \\
UK & 1.027 & 0.967 & $3.42 \%$ \\
US & 1 & 1 & $0 \%$ \\
Nordic and Japan & & & \\
Japan & 0.803 & 1.064 & $-6.02 \%$ \\
Norway & 1.032 & 1.051 & $-4.82 \%$ \\
Sweden & 0.873 & 1.047 & $-4.48 \%$ \\
\hline Note.- Observed TFP is taken from PWT 8.1 and is measured relative to US TFP (US TFP=1).
\end{tabular}


Table 3: Impact of Hiring Subsidy on TFP

\begin{tabular}{lr}
\hline \hline Country & TFP ratio $\frac{\bar{y}^{\tau} h>0}{\bar{y}^{\tau} h=0}$ \\
\hline Australia & 1.0128 \\
Canada & 1.0191 \\
France & 1.0114 \\
Germany & 1.0101 \\
Ireland & 1.0121 \\
Italy & 1.0108 \\
Japan & 1.0028 \\
New Zealand & 1.0097 \\
Norway & 1.0055 \\
Portugal & 1.0077 \\
Spain & 1.0196 \\
Sweden & 1.0048 \\
UK & 1.0099 \\
US & 1.0161 \\
\hline
\end{tabular}

Note.- Table 3 gives the ratio of TFP with a hiring subsidy $\tau_{h}=0.5\left(\bar{y}^{\tau_{h}>0}\right)$ to TFP in the model with no subsidy $\left(\bar{y}^{\tau_{h}=0}\right)$. 